https://dx.doi.org/10.4314/ijs.v19i1.6

Ife Journal of Science vol. 19, no. 1 (2017)

\title{
SURVIVAL AND GROWTH RATE OF COASTAL WATER ESCHERICHIA COLI ISOLATES IN DIFFERENT SALT CONCENTRATIONS
}

\author{
Agwu Ogochukwu A.*, Oluwagunke Theresa, Ebohon Joy \\ Department of Biological Oceanography, Nigerian Institute for Oceanography and Marine Research, 3 Wilmot Point \\ Street, Victoria Island, Lagos. ogoangela@yahoo.com, toks1x@yahoo.com joyosiuare@gmail.com \\ *Corresponding Author: ogoangela@yahoo.com \\ (Received: 9th November, 2016; Accepted: 10th June, 2017)
}

\begin{abstract}
The effect of salt concentration on the survival and growth rate of Escherichia coli isolated from Lagos Lagoon surface water was investigated. This was necessitated to ascertain the suitability of using E. coli as feacal pollution indicator in this water body which experiences fluctuation in salinity values. The salinity during the study ranged from 25.13 and $35.69 \%$. All the five E. coli isolated during the entire study period, grew luxuriantly in 0 to $4 \%$ salt concentrations with increase in optical density values of $78-93 \%$ and high $(0.005-0.45)$ growth rates within 300 minutes of incubation. The growth of these isolates at $6 \%$ salt concentration was also good with $22-77 \%$ optical density increase and growth rate range of $0.25-0.37$. However, minimal or no growth was noted at 8 to $12 \%$ salt concentrations with corresponding low increase in optical density and negligible or even negative growth rate. Although the effect of salt concentrations on the five isolates tested were comparable, the isolate (Ec2) which was isolated during the least salinity period, showed the least growth rate in all salt concentrations. These findings suggest that salinity at point of isolation can influence salt tolerance, but further affirms the use of E. coli as pollution indicator for Lagos Lagoon since they exhibited considerable halo-tolerance and survived salt concentrations up to $6 \%$.
\end{abstract}

Keywords: Escherichia coli, salt tolerance, feacal pollution indicator, salinity, growth rate, optical density.

\section{INTRODUCTION}

Escherichia coli lives in aquatic and terrestrial habitats, and is also a micro flora of intestinal and urinary tract of mammals. It is an important industrial organism and is commonly used in metabolic engineering to generate variety of products since its central carbon metabolism is well understood. E. coli has been suggested to be capable of growing in media of different nutritional status, and thrive irrespective of the amount of organic matter. This organism is regarded as a more reliable predictor of gastro intestinal illness than other bacterial indicators in water (Goh et al., 2012; How et al., 2013; Wu et al., 2014; Woods, 2015). As a member of the Enterobacteriaceae, the bacteria Escherichia coli is regarded as non-halophilic, and cannot tolerate high salt concentrations (Abdulkarim et al., 2009). Nevertheless, some strains of E. coli are halotolerant and survive in high salt concentrations. The ability to demonstrate such high osmotic pressure is possibly due to the production of amino acids (proline) in the cells (Brewer, 2000; Goh et al., 2012).

Coastal water bodies and estuarine systems are prone to salinity fluctuations due to run-off, rain and in flow of fresh water from rivers (McArthur,
2006); Nigerian coastal waters including Lagos Lagoon also exhibits this salinity variation (Agwu and Oluwagunke, 2014). An increase in the concentration of salt in an environment results in influx of salt into the cell and efflux of water molecule out of the cell leading to osmotic and ionic stress to the microbial cell (Goh et al., 2012). As an enteric bacteria, when E. coli are released from their host into the natural environments, they are exposed to different environmental stresses, such as salinity variation, nutrient availability, oxidative and osmotic stresses including temperature variation (Abdulkarim et al., 2009).

In view of the fact that E. coli are used as pollution indicator in these coastal waters with fluctuating salinity, there is need to understand the effect of varying salt concentrations on the enteric organisms when they are released to the environment. The ability of these organisms to adapt to different salt concentrations will give an idea on their survival rate during changes in the salinity of the water and the appropriateness of using them as pollution indicators during these seasons. According to Warry et al. (2008), the study of bacteria during an exponential balanced growth, reveals the effects of cellular processes to 
many bacterial physiology. Besides, growth rate of bacteria is used to measure phenotypic characteristics in environmental studies and also a measure of fitness (Hall et al., 2013). Hence this study is aimed at using the extent of growth and growth rate in various salt concentrations, to establish the effect of salt concentrations on different strains of E. coli isolated from Lagos lagoon surface water.

\section{MATERIALS AND METHODS Sample collection}

The water samples were collected monthly from the Jetty of Nigeria Institute for Oceanography and Marine Research, near the commodore channel along the Lagos Lagoon for a period of five months from November 2013-April 2014.

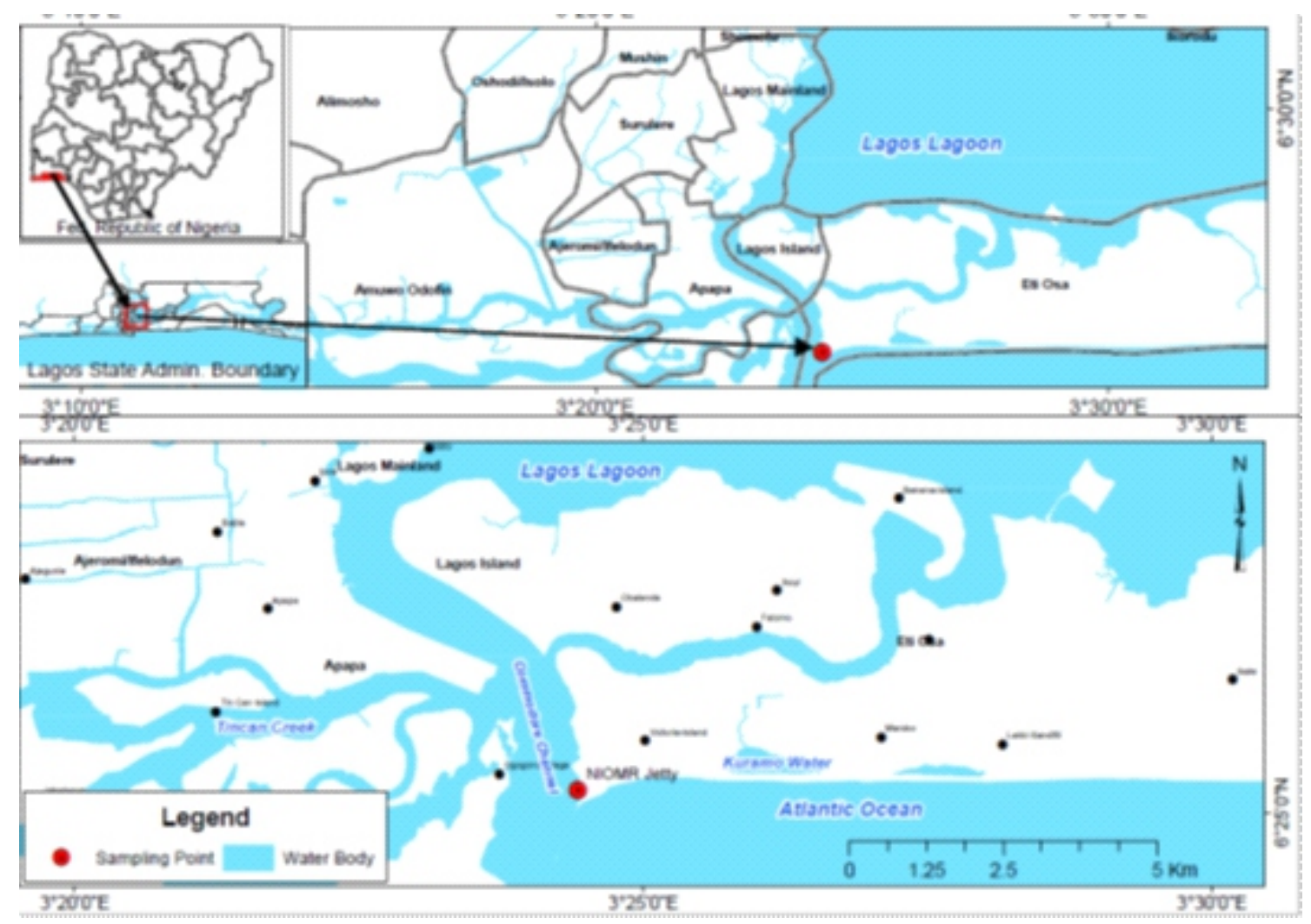

Fig. 1: Map showing the sampling point

The surface water samples were collected between 8-10 am in sterilized sampler bottles (1000 ml). A portion of the water sample was used to determine the Physico-chemical parameters employing the Horiba U-10 multipurpose water sampler, while the remaining water sample was immediately transported to the laboratory for bacteriological analysis.

\section{Isolation and Identification of bacterial isolates}

The initial isolation of the bacteria was carried out with the five tube most probable number (MPN) method using Lauryl Sulphate Broth (Oxoid, Germany). After 24 hour incubation at $37^{\circ} \mathrm{C}$, positive tubes (tubes showing gas production) were selected and aliquots $(0.1 \mathrm{ml})$ of the culture, inoculated onto Eosin Methylene Blue Agar (Oxoid, Germany), and further incubated for 24 hours at $37^{\circ} \mathrm{C}$. Colonies with green metallic sheen were picked, and purified. The IMViC (Indole, Methylred, Voges-Proskauer and Citrate) tests were used to further confirm E. coli isolates among the bacterial species and these were stored on Nutrient Agar (Biolife, Italy) slants for further study.

\section{Bacterial Salt tolerance and growth monitoring}

The salt tolerance experiment was done as previously described by Agwu and Oluwagunke (2014). The pure cultures of five (5) Escherichia coli 
strain isolated at different period were grown in Luria Bertani medium for 24 hours at $37^{\circ} \mathrm{C}$. Thereafter, the cells were harvested after centrifugation at $4000 \mathrm{rpm}$ for 7 minutes, washed with phosphate buffer and re-suspended in phosphate buffer solution. The bacterial suspensions $(0.1 \mathrm{ml})$ with optical density of 1 unit were used to inoculate tubes containing $5 \mathrm{ml}$ Luria Bertani Broth of different salt concentrations $(0$, $2,4,6,8,10$ and $12 \%$ ). All experiments replicated, with un-inoculated tubes serving as control experiments. The initial absorbance of each culture was measured immediately after inoculation and the bacterial growth were monitored until stationary phase when increase in turbidity was not noticed, by measuring the absorbance of the cultures after 60, 120, 180, 240 and 300 minutes of incubation using a spectrophotometer (Lamotte Maryland, USA) at a wavelength of $600 \mathrm{~nm}$.

\section{RESULTS}

Throughout the duration of this study, the surface water salinity varied between 25.13 and 35.69 (Table 1). The highest dissolve oxygen value observed was $6.16 \mathrm{mgl}^{-1}$, while the least value was 5.27. There was not much difference in the water temperature with the average value of $29.59{ }^{\circ} \mathrm{C}$. The $\mathrm{pH}$ value ranged between 8.05 to 8.17 also, the average value for conductivity and alkalinity was $48.26 \mu \mathrm{ohms}$ and $16.29 \mathrm{mg} \mathrm{Ca} \mathrm{CO}_{3}{ }^{-1}$ respectively.

Table 1 Physico-chemical parameters of surface water during the sampling period

\begin{tabular}{|c|c|c|c|c|c|c|}
\hline $\begin{array}{l}\text { Sampling } \\
\text { Time }\end{array}$ & $\begin{array}{c}\text { DO } \\
\left(\mathrm{mgl}^{-1}\right)\end{array}$ & $\begin{array}{c}\text { Water } \\
\text { TEMP } \\
\left({ }^{\circ} \mathrm{C}\right) \\
\end{array}$ & $\begin{array}{l}\text { SAL } \\
(\% 0)\end{array}$ & $\mathrm{pH}$ & $\begin{array}{c}\text { CON } \\
(\mu \mathrm{ohms})\end{array}$ & $\begin{array}{l}\mathrm{ALK} \\
\left(\mathrm{mg} \mathrm{Ca} \mathrm{CO}{ }^{1-1}\right)\end{array}$ \\
\hline November & 5.6 & 29.88 & 35.69 & 8.05 & 54 & 16.25 \\
\hline December & 6.3 & 28.38 & 25.13 & 8.17 & 38.96 & 14.63 \\
\hline February & 6.16 & 29.41 & 32.64 & 8.16 & 49.68 & 18.13 \\
\hline March & 5.42 & 29.98 & 33.77 & 8.11 & 50.69 & 17.7 \\
\hline April & 5.27 & 30.29 & 32.04 & 8.16 & 47.96 & 14.78 \\
\hline $\begin{array}{l}\text { Mean } \pm \\
\text { STDEV }\end{array}$ & $\begin{array}{r}5.75 \\
\pm 0.456 \\
\end{array}$ & $\begin{array}{r}29.59 \\
\pm 0.745 \\
\end{array}$ & $\begin{array}{r}31.85 \\
+4.008 \\
\end{array}$ & $\begin{array}{c}8.13 \\
\pm 0.050 \\
\end{array}$ & $\begin{array}{r}48.26 \\
+5.645 \\
\end{array}$ & $\begin{array}{r}16.29 \\
\pm 1.613 \\
\end{array}$ \\
\hline
\end{tabular}

Key: DO, Dissolved oxygen; TEMP, Temperature; SAL, Salinity; CON, Conductivity; ALK, Alkalinity

Extent of growth density and growth rate of Ec1 at different salt concentrations

The first E. coli strain (Ec1) isolated in November grew luxuriantly during the initial 240 minutes of incubation for the 0 to $4 \%$ salt concentration. However, poor or no visible growth was observed for the higher salt concentrations (8 to $12 \%$ ). At the end of the 300 hour incubation period, the culture with $2 \%$ salt concentration had the highest optical density (Figure 2A), this was closely followed by $0 \%$, then, 4 and $6 \%$ salt concentration cultures.

The corresponding growth rate of the isolate during the growth period (Table 2) was also high during the initial 0 to 120 minutes for 0 to $6 \%$ salt concentrations. The highest growth rate observed (1.227) was in $0 \%$ salt concentration at $60-120$ minute; meanwhile, the higher salt concentrations had very low and even negative growth rate values. Two-way analysis of variance of the growth rate at the different time and salt concentrations showed that there was no significant variation $(p=0.3227)$ in the growth rate with time however, there was a significant variation $(p=0.0306)$ in the growth rate at the different salt concentrations.

Extent of growth density and growth rate of Ec2 at different salt concentrations

The growth culture of the second strain of E. coli 
(Ec2) also denoted profuse growth of the organism at $0,2,4$ and $6 \%$ salt concentrations with a rise in the optical density of initial values of between 0.189 and 0.223 to final values that ranged from 0.594 to 1.774 (Figure 2B). The highest OD value was however, noted for the $2 \%$ salt concentration. On the other hand, there was little or no change in the optical density values of the culture in $8 \%$ (0.223 to 0.301$) ; 10 \%$ (0.214 to $0.224)$ and $12 \%(0.215$ to 0.218$)$ salt concentrations.

Table 2 Growth rate of the E. coli strain (Ec1) in Luria Bertani Broth during the three hundred minutes incubation

\begin{tabular}{|c|c|c|c|c|c|c|c|}
\hline \multirow[t]{2}{*}{$\begin{array}{l}\text { Time } \\
\text { (Minutes) }\end{array}$} & \multicolumn{7}{|c|}{ Salt Concentration } \\
\hline & $0 \%$ & $2 \%$ & $4 \%$ & $6 \%$ & $8 \%$ & $10 \%$ & $12 \%$ \\
\hline $0-60$ & 0.883 & 0.428 & 0.229 & 0.426 & -0.0021 & 0.232 & 0.348 \\
\hline $60-120$ & 1.227 & 1.083 & 0.601 & 0.618 & 0.048 & -0.241 & -0.287 \\
\hline $120-180$ & 0.404 & 0.595 & 0.693 & -0.279 & 0.108 & 0.198 & -0.081 \\
\hline $180-240$ & 0.213 & 0.278 & 0.238 & 0.271 & 0.039 & -0.056 & 0.312 \\
\hline $240-300$ & -0.002 & 0.049 & 0.486 & 0.463 & 0.093 & -0.036 & -0.238 \\
\hline
\end{tabular}

Table 3 Growth rate of E. coli strain (Ec2) in Luria Bertani Broth during the three hundred minutes incubation

\begin{tabular}{|c|c|c|c|c|c|c|c|}
\hline \multirow[t]{2}{*}{$\begin{array}{l}\text { Time } \\
\text { (minutes) }\end{array}$} & \multicolumn{7}{|c|}{ Salt concentrations } \\
\hline & $0 \%$ & $2 \%$ & $4 \%$ & $6 \%$ & $8 \%$ & $10 \%$ & $12 \%$ \\
\hline $0-60$ & 0.007 & 0.006 & 0.004 & 0.001 & 0.001 & 0.0004 & 0.0073 \\
\hline $60-120$ & 0.020 & 0.018 & 0.012 & 0.004 & -0.001 & 0.0007 & $-1.6 \mathrm{E}-14$ \\
\hline $120-180$ & 0.006 & 0.009 & 0.008 & 0.005 & 0.003 & -0.0010 & -0.008 \\
\hline $180-240$ & 0.002 & 0.002 & 0.004 & 0.003 & 0.003 & 0.0003 & -0.0006 \\
\hline 240-300 & 0.004 & 0.001 & 0.001 & 0.002 & 0.003 & 0.0004 & 0.0007 \\
\hline
\end{tabular}

The growth rate obtained during the culture of Ec2 was highest during the 60-120 minutes period of the culture especially for lower $(0-6 \%)$ salt concentrations (Table 3). The growth rate also decreased with increase in salt concentration and time. There was a significant difference in the growth rate at the various concentration with $\mathrm{p}=$ 0.0306 , meanwhile, the growth rate did not show any significant difference $(\mathrm{p}=0.101)$ with time.

\section{Extent of growth density and growth rate of} Ec3 at different salt concentrations

There was an obvious increase of between 80 to $94 \%$, in the optical density of the culture of Ec3 during the entire period of incubation, depicting good growth of the organism in salt concentrations from 0 to 6\% (Figure 2C). As was also noted for the other isolates (Ec1 and Ec2), there was little or no visible growth in the cultures with high salt concentrations $(8-12 \%)$, the optical density barely showed 0 to $7.5 \%$ increase.

Isolate Ec3 exhibited the utmost growth for the $0 \%$ salt concentration during the first hour of incubation (Table 4). The other salt concentrations $(2-12 \%)$ had the highest growth rate at 60 to 120 minutes incubation period. The growth rate showed a significant difference at the different salt concentrations $(p=0.0184)$ and time $(p=0.0207)$. 

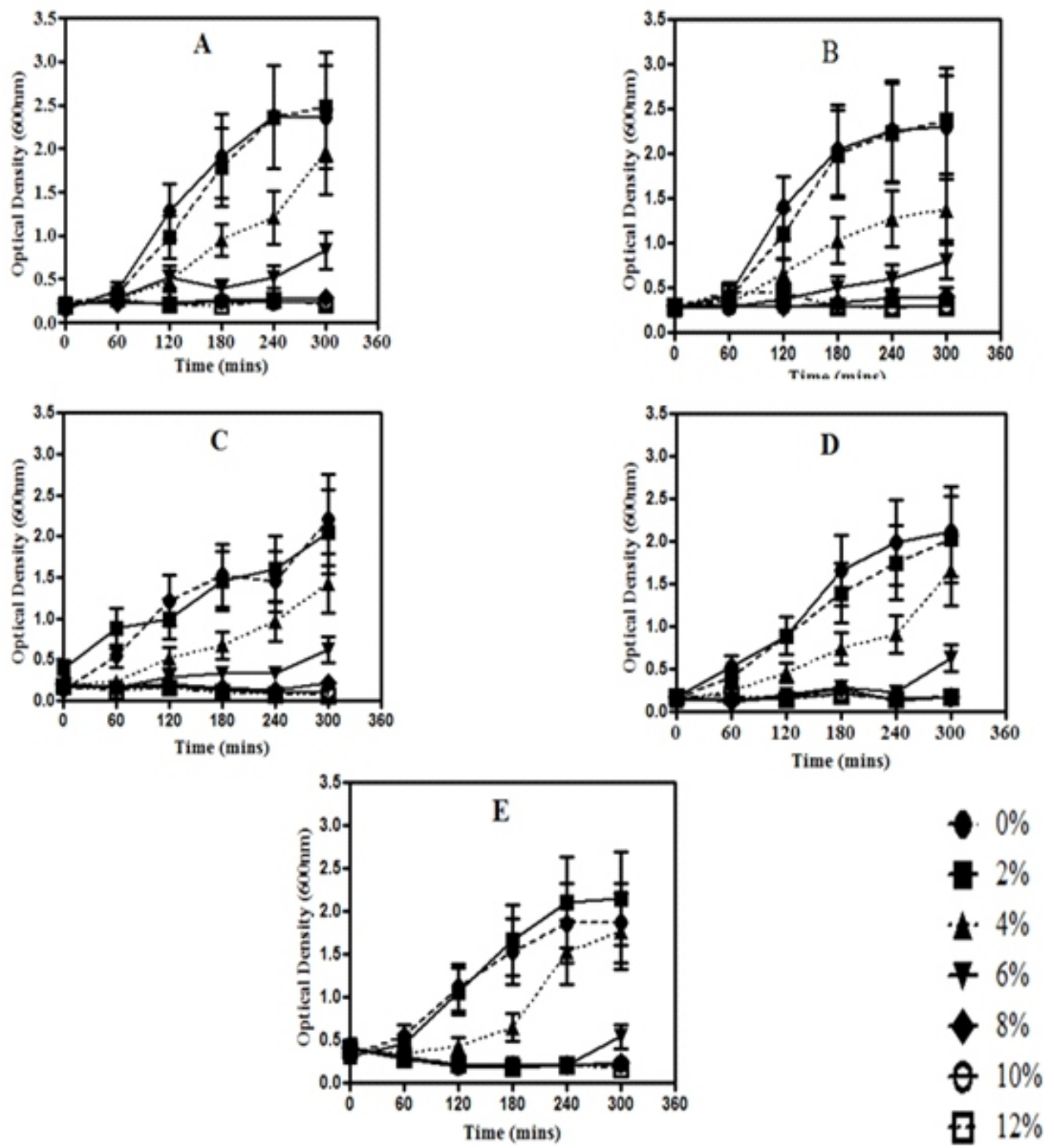

\section{Figure 2 Growth curve of $E$. coli isolates (A:Ec1; B:Ec2; C:Ec3; D: Ec4 and E :Ec5) in different salt concentrations during the $\mathbf{3 0 0}$ minutes culture}

Table 4 Growth rate of E. coli strain (Ec3) in Luria Bertani Broth during the three hundred minutes incubation

\begin{tabular}{|c|c|c|c|c|c|c|c|}
\hline \multirow[t]{2}{*}{$\begin{array}{l}\text { Time } \\
\text { (Minutes) }\end{array}$} & \multicolumn{7}{|c|}{ Salt concentrations } \\
\hline & $0 \%$ & $2 \%$ & $4 \%$ & $6 \%$ & $8 \%$ & $10 \%$ & $12 \%$ \\
\hline $0-60$ & 0.024 & -0.014 & 0.005 & -0.001 & -0.003 & -0.003 & -0.006 \\
\hline $60-120$ & 0.014 & 0.016 & 0.013 & 0.009 & 0.003 & 0.002 & 0.004 \\
\hline $120-180$ & 0.004 & 0.006 & 0.005 & 0.002 & -0.004 & -0.005 & -0.008 \\
\hline $180-240$ & -0.001 & 0.002 & 0.006 & $-3 E-05$ & -0.004 & -0.005 & -0.003 \\
\hline $240-300$ & 0.007 & 0.004 & 0.006 & 0.011 & 0.009 & 0.002 & -0.003 \\
\hline
\end{tabular}


Table 5 Growth rate of E. coli strain (Ec4) in Luria Bertani Broth during the three hundred minutes incubation

\begin{tabular}{|c|c|c|c|c|c|c|c|}
\hline \multirow[t]{2}{*}{$\begin{array}{l}\text { Time } \\
\text { (Minutes) }\end{array}$} & \multicolumn{7}{|c|}{ Salt concentrations } \\
\hline & $0 \%$ & $2 \%$ & $4 \%$ & $6 \%$ & $8 \%$ & $10 \%$ & $12 \%$ \\
\hline $0-60$ & 0.018 & 0.016 & 0.009 & -0.001 & -0.007 & -0.002 & 0.001 \\
\hline $60-120$ & 0.009 & 0.013 & 0.011 & 0.007 & 0.007 & 0.002 & -0.004 \\
\hline $120-180$ & 0.010 & 0.007 & 0.008 & 0.006 & 0.007 & 0.005 & 0.004 \\
\hline $180-240$ & 0.003 & 0.004 & 0.003 & -0.004 & -0.012 & -0.005 & -0.005 \\
\hline $240-300$ & 0.001 & 0.003 & 0.010 & 0.017 & 0.005 & -0.0002 & 0.003 \\
\hline
\end{tabular}

Extent of growth density and growth rate of Ec4 at different salt concentrations

The extent of growth of isolate Ec4 in the cultures with salt concentrations 0 to $4 \%$ resulted in about $91 \%$ increase in the optical density values. Also, at $6 \%$ salt concentration, the optical density increased from 0.15 to 0.63 corresponding to $76.6 \%$ increase. Conversely, there was less than $3 \%$ increase in the optical density of the cultures with 8 to $12 \%$ salt concentrations, indicating minimal or complete absence of cell growth (Figure 2D).

The growth rate of Ec4 in the various salt concentrations was similar to that of the other isolates (Table 5). The highest growth rate of 0.018 was obtained for the $0 \%$ salt concentration during the $0-60$ minutes culture period. Generally, the growth rate declined with increase in salt concentration and time; the variation in growth rate was significantly different both in salt concentrations $(p=0.019)$ and time $(p=0.022)$.

\section{Extent of growth density and growth rate of} Ec5 at different salt concentrations

This fifth E. coli strain (Ec5) isolated in the month of April showed the best prolific growth at $2 \%$ salt concentration with optical density increasing from 0.313 to 2.15 during the 300 minutes incubation period. There was also a remarkable growth for the 0 and $4 \%$ salt concentrations. Nevertheless, the other higher salt concentrations (6 to $12 \%) \mathrm{did}$ not show much visible growth (Figure 2E).

In accordance with the extent of growth noted for this isolate (Ec5), the growth rates at 0 to $6 \%$ salt concentrations were comparable at different periods of incubation (Table 6). Although, the variations in the growth rate at the different concentrations was significantly different $(p=$ 0.038), there was no significant difference with time $(\mathrm{p}=0.558)$.

\section{Comparison of the growth rate of all (5) isolates}

The overview of the growth rate of the five E. coli strains studied (Table 7), further showed that their growth rate increased as the concentration of salt increased from 0 to $4 \%$, but declined as the salt concentrations increased further from 6 to $12 \%$. The Two-way analysis of variance revealed that the growth rate of the five isolates differed significantly with $p=0.0040$. Furthermore, the difference in the growth rate of the isolates at the various salt concentrations was extremely significant $(\mathrm{P}<0.0001)$. All the isolates had their highest growth rate at $4 \%$ salt concentration, except Ec2, which had the maximum growth rate of 0.00514 at $2 \%$ salt concentration. This organism however exhibited the least growth rate among all the five isolates tested in all the different salt concentrations. On the other hand, the highest growth rate of 0.4547 was observed with Ec4 at $4 \%$ salt concentration. 
Table 6 Growth rate of E. coli strain (Ec5) in Luria Bertani Broth during the three hundred minutes incubation

\begin{tabular}{|c|c|c|c|c|c|c|c|}
\hline \multirow[t]{2}{*}{$\begin{array}{l}\text { Time } \\
\text { (Minutes) }\end{array}$} & \multicolumn{7}{|c|}{ Salt concentrations } \\
\hline & $0 \%$ & $2 \%$ & $4 \%$ & $6 \%$ & $8 \%$ & $10 \%$ & $12 \%$ \\
\hline $0-60$ & 0.009 & 0.006 & -0.002 & -0.005 & -0.006 & -0.005 & -0.005 \\
\hline $60-120$ & 0.012 & 0.014 & 0.004 & -0.007 & -0.006 & -0.006 & -0.004 \\
\hline $120-180$ & 0.005 & 0.007 & 0.007 & 0.002 & 0.0008 & -0.002 & -0.004 \\
\hline $180-240$ & 0.003 & 0.004 & 0.014 & -0.001 & -0.0009 & 0.002 & 0.002 \\
\hline $240-300$ & $\begin{array}{c}4.2 \mathrm{E}- \\
05\end{array}$ & 0.0004 & 0.003 & 0.016 & 0.0029 & 0.001 & -0.003 \\
\hline
\end{tabular}

Table 7 Exponential Growth rate of E. coli isolates during the three hundred minutes culture period

\begin{tabular}{|c|c|c|c|c|c|}
\hline $\begin{array}{c}\text { Salt } \\
\text { Concentrations } \\
(\%)\end{array}$ & Ec1 & Ec2 & Ec3 & Ec4 & Ec5 \\
\hline 0 & 0.3063 & 0.004587 & 0.2991 & 0.3087 & 0.2553 \\
\hline 2 & 0.3423 & 0.005142 & 0.2435 & 0.3287 & 0.2936 \\
\hline 4 & 0.4443 & 0.00479 & 0.3896 & 0.4547 & 0.4074 \\
\hline 6 & 0.248 & 0.003957 & 0.2749 & 0.3692 & 0.04449 \\
\hline 8 & 0.0627 & 0.001188 & -0.01859 & 0.02313 & -0.1448 \\
\hline 10 & 0.009263 & 8.93E-05 & -0.1082 & 0.006825 & -0.1604 \\
\hline 12 & -0.00094 & -0.00086 & -0.1715 & -0.00981 & -0.1816 \\
\hline
\end{tabular}

\section{DISCUSSION}

Lagos Lagoon as a coastal water experiences fluctuation in salinity, thus this study was carried out to determine the extent to which Escherichia coli isolates from this water body can tolerate sodium chloride concentrations in a laboratory medium. The surface water salinity varied during this study, Escherichia coli were also readily isolated from the surface water during these different salinity values and all the isolates grew on Luria Bertani Broth with 0 to $6 \%$ sodium chloride concentrations. Kunin et al. (1993) had stated that most strains of Escherichia coli can grow in synthetic minimal media containing salts, trace metals and a simple source of carbon and nitrogen such as glucose and ammonium. Furthermore, Low et al. (2013) had shown that Nutrient Broth, Luria Bertani Broth and Brain Heart Infusion Broth are able to support growth of E. coli for 4 weeks in culture before a decline in viable cell count. They also mentioned that some unique characteristics such as simple biology structure, short generation time, and ability to grow on several basic growth media make Escherichia coli easy to study and thus, generally regarded as a model organism for prokaryotic systems.

In this study, the five E. coli isolates showed salt tolerance of up to $6 \%$, this corroborates earlier studies were strains of $E$. coli had been able to grow on salt concentrations of between 0 and $8 \%$ (Brewer, 2000; Vera and Stojanović, 2003; Hrenovic and Ivankovic, 2009). The ability of these isolates to show significant growth in sodium chloride concentrations up to $6 \%$ can possibly be because the bacteria were grown in a nutrient rich media, where the effect of $\mathrm{NaCl}$ was hindered. There is a possibility of $\mathrm{NaCl}$ ions binding to organic matter in the growth medium which could consequently reduce the negative influence of the $\mathrm{NaCl}$ to the bacteria as opposed to when the organisms are grown in nutrient deficient media and growth is obviously inhibited. In addition, the growth rate of bacteria in a nutrient rich medium is independent of the concentrations of nutrient, but in a nutrient 
limiting environment, growth rate is directly proportional to the extracellular concentration of the limiting nutrient (Warry et al., 2008; Hrenovic and Ivankovic, 2009). As had earlier been shown by Goh et al. (2012) that E. coli can easily adapt to high salt concentrations, the isolates in this study also demonstrated rapid adaptation with the first two isolates Ec1 and Ec2 showing a short lag phase of growth during the first hour of incubation (Figure 2A and 2B) while the other three isolates particularly Ec3 and Ec4, showed obvious increase in optical density during the initial incubation period (Figure 2C, D and E) since observable lag phase was noted. Sévin and Sauer (2014), noted that the principal mechanism of bacterial adaptation to fluctuating environmental solute concentration, is by adjustment of their cytoplasmic osmolality. Meanwhile, the ability to adapt to different salt concentrations could also infer adaptation of these isolates to other chemical substances such as antibiotics and food preservatives (Saenz et al., 2004; Goh et al., 2012).

It was generally observed that the higher salt concentration cultures of the E. coli isolates did not show increase in optical density which resulted in very low and even negative growth rate values (Tables 2 to 6). This was not surprising because microbial growth can be negatively affected by the presence of sodium chloride. Salt has the capacity to decrease the water activity $\left(a_{w}\right)$ of an environment and reduction of $a_{w}$ below optimum value for growth, usually leads to linear decrease in growth rate. In addition, slow or negative growth rates are a result of the absence of growth or decrease in turbidity due to cell lysis and inconsistent optical density (Brewer, 2000; Petrovic et al., 2002; Neysens et al., 2003; Hall et al., 2013; Wu et al., 2014; Woods, 2015). Comparison of the growth rates of all five isolates revealed that Ec2 had the least growth rate, among all the isolates at the different salt concentrations (Table 7). Interestingly, this bacterium was isolated in December, a period with the least salinity value of 25.13 (Table 1); this suggests that the salinity of an environment might influence the ability of the resident microbes to tolerate salt.

According to Hall et al., (2013) growth rate has historically been used as a measure of fitness of organisms in the environment; hence the capabilities exhibited by these organisms, suggest that they have the ability to survive in environments of changing salinity and thus are suitable as fecal indicator bacteria. Nevertheless, it is noteworthy that apart from salinity, other factors such as nutrient availability, microbial antagonism and antibiotic substances creates limiting environmental conditions which affect the survival of enteric bacteria in the aquatic ecosystem (Warry et al., 2008; Hrenovic and Ivankovic, 2009). Moreover, the presence of nutrients and osmotic compounds in coastal areas help fecal bacteria to survive and tolerate salinity (Pommepuy etal., 1992).

\section{CONCLUSION}

Lagos Lagoon experiences fluctuation in salinity and the E. coli isolates from the surface water of this coastal water body showed the ability to survive and grow at salt concentrations of 0 to $6 \%$. However, a subtle effect of the salinity at the time of isolation on salt tolerance was noted. Future work will attempt to understand the mechanism of salt tolerance of these isolates.

\section{REFERENCES}

Abdulkarim, S.M., Fatimah, A.B. and Anderson, J.G. 2009. Effect of salt concentrations on the growth of heat-stressed and unstressed Escherichia coli. J. Food Agri. Environ. 7 (3 and 4): 51-54.

Agwu, O., and Oluwagunke T. 2014. Halotolerance of Heterotrophic Bacteria Isolated from Tropical Coastal Waters. Int. J. Sci. Bas. Appl. 16(2): 224-231.

Brewer, M.S. 2000. Traditional preservativeSodium Chloride. In Encyclopedia of Food Microbiology. Robinson, R.K., Batt, C.A. and Patei, P.D. (editors). Academic Press, New York, pp 1723-1728.

Goh, D. J. W., How, J. A., Lim, J. Z. R., Ng, W. C., Oon, J. S., Lee, C. H., and Ling, M. H. T. 2012. Gradual and Step-wise Halophilization Enables Escherichia coli ATCC 8739 to Adapt to $11 \% \mathrm{NaCl}$. Electron. Physician 4(3): 527-535.

Hall, B. G., Acar, H., Nandipati, A., and Barlow, M. 2013. Growth Rates Made Easy. Mol. Biol. Evol. 12: 1-7.

How, J. A., Lim, J. Z. R., Goh, D. J. W., Ng, W. C., 
Oon, J. S. H., Lee, K. C., Lee, C. H. and Ling, M. H. T. 2013. Adaptation of Escherichia coli ATCC 8739 to 11\% NaCl. DatasetPap. Biol. pp 1-7.

Hrenovic, J. and Ivankovic T. 2009. Survival of Escherichia Coli and Acinetobacter Junii at Various Concentrations of Sodium Chloride. Eur Asian J. Biosci. 151 (3): 144-51.

Kunin, M., Tong, H. and Maher, W. E. 1993. Naturally-occurring, osmo-remediaI variants of Escherichia coli. J. Med. Microbiol. 38: 216-221.

Low, S. X. Z., Aw, Z. Q., Loo, B. Z. L., Lee, K. C., Oon, J. S. H., Lee, C. H., \& Ling, M. H. T. 2013. Viability of Escherichia coli ATCC 8739 in Nutrient Broth, Luria-Bertani Broth and Brain Heart Infusion over 11 Weeks. Electron. Physician 5: 5576-581.

McArthur, J.V. 2006. Microbial Ecology: An evolutionary approach. Elsevier Academic press: USA. 171pp.

Neysens, P., Messens, W. and De Vuyst, L. 2003. Effect of Sodium Chloride on Growth and Bacteriocin Production by Lactobacillus Amylovorus DCE 471. Int. J. Food Microbiol. 88: 29-39.

Petrovič, U., Gunde-Cimerman, N. and Plemenitaš, A. 2002. Cellular Responses to Environmental Salinity in the Halophilic Black Yeast Hortaea Werneckii, Mol. Microbiol. 45 (3): 665-72.

Pommepuy, M, Guillaud J. F., Dupray, E., Derrien,
A., Le Guyader, F. and Cormier, M. 1992. Enteric Bacteria Surviv Al Factors, Wat. Sci. Tech. 25 (12): 93-103.

Saenz, Y., Brinas, L., Dominguez, E., Ruiz, J., Zarazaga, M., Vila, J. and Torres, C. 2004. Mechanisms of resistance in multipleantibiotic-resistant Escherichia coli strains of human, animal, and food origins..Antimicrob. Ag. Chemo. 48: 3996-4001.

Sévin, D.C. and Sauer, U. 2014. Ubiquinone accumulation improves osmotic-stress tolerance in Escherichia coli. Nat. Chem. Biol. 10:266-272.

Vera. K. and Stojanović, L. 2003. The Effect of Salt Concentration and $\mathrm{pH}$ on the Survival and Growth of E. coli O157:H7 in white Cheese and Trypticase Soy Broth. Acta Veterinaria 53 (5-6): 411-418.

Warry, N. El, Khorasani, S. and Mazanderani, A., 2008. Controlling the Growth Rate of Escherichia coli by Limiting the Supply of Carbon in an Amylose-Amylase Nutrient System, J. Exp. Microbiol. Immunol. 12:1-6.

Wood, J. M. 2015. Bacterial Responses to Osmotic Challenges, J. Gen. Physiol. 145 (5): 381-88

Wu, X., Altman, R., Eiteman, M. A. and Altman, E. 2014. Adaptation of Escherichia coli to Elevated Sodium Concentrations Production, Appl. Environ. Microbiol. 80(9): 2880-2888. 